\title{
When strategic plans fail to lead. A complexity acknowledging perspective on decision-making in Urban Development Projects - The case of Kortrijk (Belgium)
}

\author{
T. Block ${ }^{1}$, K. Steyvers ${ }^{2}$, S. Oosterlynck ${ }^{3}$, H. Reynaert ${ }^{4}$, F. De Rynck ${ }^{4}$ \\ ${ }^{1}$ Urban Policy Research Centre, Ghent University, Belgium \\ ${ }^{2}$ Centre for Local Politics, Ghent University, Belgium \\ ${ }^{3}$ Department of Sociology, University of Antwerp, Belgium and Post-doctoral Fellow of Fund for Scientific Research - \\ Flanders, Department of Architecture, Urban Design and Planning, KU Leuven, Belgium \\ ${ }^{4}$ Centre for Local Politics, Ghent University, Belgium \\ ${ }^{5}$ Faculty of Business and Public Administration, University College Ghent, Belgium
}

Correspondence Address: Thomas Block, Urban Policy Research Centre, Ghent University, Poel 16, 9000 Ghent, Belgium, Email: Thomas.Block@UGent.be

\begin{abstract}
Nowadays, cities formulate long term strategies to address the challenges and opportunities they face. Numerous strategic plans or planning instruments are developed to this purpose. In this article we want to examine the role, impact and relevance of these types of plans in decision-making processes concerning urban development projects (UDPs) in the Flemish Region of Belgium. To what extent do strategic plans succeed in capturing and steering the complexity of spatial interventions in contemporary urban contexts? We argue that a complexity acknowledging perspective provides a more realistic and adequate view here by seeing strategic plans as only one among many elements in the set of tangled inter- and intrastrategic processes which together determine UDPs. A comparative and qualitative case study was carried out in the city of Kortrijk. The decision-making of three UDP's was studied thoroughly. Interviewing key actors and analysing policy documents helped us to (re)construct the complex decision-making processes and to stipulate the meaning of all involved formal plans and planning tools.
\end{abstract}

\section{Introduction}

The rise of new public management (amongst other factors) has led planning instruments of all kinds to become increasingly popular in the public sector (Hood, 1991; Pollitt et al., 2000; Teisman, 2005), not the least in the field of Urban Policy (van Helden et al., 2003; Pinson, 2009). Researchers disagree fiercely however on the role strategic plans (can) play in public decision-making processes. Some argue that these plans have a high capacity to steer decision-making processes and the latter are seen in terms of a linear process of neatly separated successive phases. Others are more sceptical about the role of strategic plans in complex and hybrid decision-making processes. In this article, we focus on the role of strategic plans in the context of urban development projects. To map the relevance, function and impact of these plans we use a perspective that duly acknowledges the complexity of decision-making.

By urban development projects (UDPs) we mean physical-spatial interventions that have pronounced consequences for urban development (Boudry et al., 2006: 12). Since the late 1980s the 'project mode' has become increasingly popular in urban planning (De Sola Morales, 1989; Salet et al., 2006). According to political geographers, UDPs have been the first and foremost instruments used in 
profiling and repositioning localities within the boundaries of intercity competition (MacLeod et al., 1999; Moulaert, 2002; Swyngedouw et al., 2002). Large-scale projects are being set up in an idealtypical form across networks or coalitions that may be aligned with the concept of 'urban governance'. Local politicians, top-echelon civil servants, autonomous municipal organisations, supra-local governments, investment companies, etc. are in such cases more or less intertwined within hybrid and autonomous coalitions (Pinson, 2006).

The notion of 'strategic plans' covers a wide array of allegedly policy steering instruments. In Flemish urban policy, strategic plans and planning instruments are mobilised on various spatial scales and within and across policy domains. Hence, we do not reserve the concept 'strategic' for one single specified spatial scale or policy domain (Mintzberg et al., 1998). On the level of the city and transcending different policy domains, the most common strategic plans are coalition agreements and strategic multi-annual plans. Coalition agreements are often very important in multiparty and coalition government systems. This is certainly the case in Flemish local councils, in which different political parties negotiate with each other on the basis of their respective electoral programs and agree on a coalition agreement in which their aims are more often than not embedded in an overarching strategic vision for the future local policy. While doing so, they take into account their grass roots support and electoral basis, amongst others by claiming those policy areas and projects relevant to them. This is complemented by a mode of decision-making largely dominated by political parties that have their strongholds in the executive College of Mayor and Aldermen (CMA), the dominant local political institution. Hence, the coalition agreement should function as a shared and almost natural frame of reference. Strategic multi-annual plans in Flemish cities exist from a financial and strategic note prepared, steered and (in time) reviewed by the municipal secretary, the financial manager and the Management Team. Those multi-annual plans have therefore a more administrative character and they sometimes seems to have a lack of considerable political support in certain Flemish cities (Reynaert et al., 2008) ${ }^{1}$. Also at the city level, but then in the policy domain of spatial planning, the main strategic document is the municipal spatial structural plan, which stipulates the desired spatial development of a particular city or municipality. Finally, there are a number of strategic plans that are applied specifically within an UDP such as protocols, public-private partnerships, project master plans, etc. According to Faludi, project plans are less open and flexible and more strongly focused than their counterparts on the city level (Faludi, 2000).

In what follows, we first describe the perspective we use to reconstruct the complex decision-making processes of UDPs. We propose to adopt a perspective that does not consider strategic plans as effective tools to impose order on complexity, but is rather sceptical on the order-seeking capacity of strategic plans and rather acknowledges the complexity of decision-making processes (Teisman, 2005). Taking this 'complexity-acknowledging' perspective as a starting point, we develop a conceptual framework to analyse decision-making processes in urban development projects and formulate hypotheses on the relation between strategic plans and decision-making processes. We then move on to test this framework and our hypotheses in the case of the Flemish city of Kortrijk. By means of various qualitative research techniques we reconstructed the decision-making processes for three UDPs in Kortrijk. We complete this article by offering some general conclusions and reflections about the role and impact of the planning tools from a complexity-acknowledging perspective that come forward from combining the findings from our case study with the more general starting framework, while at the same time situating such instruments within the broader context of decision-making processes.

\footnotetext{
${ }^{1}$ The Municipal Decree of 2005 obliges Flemish cities and municipalities to draw up a cross-sectoral strategic plan that covers their entire legislative term (i.c. 6 years) and identifies ideally their main objectives.
} 


\section{Perspective and research questions}

\subsection{To a complexity-acknowledging perspective}

Within the literature, there is a variety of classifications of theories that are concerned with the complexity of decision-making processes (e.g., Allison, 1971; Chaffee, 1985; Mintzberg et al., 1998; Bowman, 1995; Johnson et al., 2002). Most relevant to our analysis here is Teisman's 'ideal-typical' distinction (based on system-theoretical thinking) between an order-seeking and a complexityacknowledging perspective (Teisman, 2005). According to the first perspective, complex systems are intricate variants of simple systems and are hence knowable and can be steered and controlled with strong leadership, solid coordination, powerful (planning)instruments and/or high-quality guidance information. In the complexity-acknowledging perspective, it is the composite character of complex systems that commands the central focus. From this perspective, systems are composed of multiple subsystems that are loosely held together and develop as the segments influence each other in unpredictable ways. Here, chaos reigns within an environment where variables do indeed impact upon, and interact with, one another, yet with barely a presence of stable causal connections (Stacey, 1996; Teisman, 2005). The order-seeking and complexity-acknowledging perspective approach strategic plans differently and give them a different meaning in decision-making processes. We tend to find the order-seeking perspective with more rational, mechanical, instrumental and/or linear approaches to decision-making, while a complexity-acknowledging perspective is strongly present in incremental, organic and/or chaotic approaches. The distinction can also to a large extent be traced back to the difference between prescriptive or normative theories on the one hand, and descriptive theories on the other hand. This difference frequently renders discussions about such theories somewhat artificial (Smith et al., 1980). We are also fully aware that most theories can be positioned on this continuum somewhere in between these rather naïve extremes.

Researchers who study decision making processes of UDPs and the meaning of strategic plans always have (and need) a perspective. "We cannot depict decision making without making assumptions about its appearance" (Teisman, 2000: 938). Implicit (or seldom explicit) assumptions determine the perspective used to analyse the research object and therefore selectivity occurs. "What we see and judge to be important and accept as adequate depends not only on the evidence available but also on the 'conceptual lenses' through which we look at the evidence" (Allison, 1971: 2). As already mentioned we started from a complexity-acknowledging perspective to answer our central research question, namely: "To what extent do strategic plans succeed in capturing and steering the complexity of spatial interventions in contemporary urban contexts?" We did not have the intention to discover the 'best' perspective, but to examine what we can learn from this rather alternative ${ }^{2}$ and holistic point of view. The aim of our research, then, is to analyse to what extent a complexityacknowledging perspective allows us also to observe and identify those important and more refined mechanisms at work in decision-making processes of UDPs.

According to our complexity-acknowledging perspective any decision concerning UDPs is seen as happening within a tangled series of decisions in which formal decisions and decision-makers do indeed play a role, but this role depends to a large degree to the meaning given to the decisions in the many interactions among the actors involved (Simon, 1947; Flyvbjerg, 1998; Teisman, 2000). This viewpoint became very popular with spatial planners through the communicative turn in planning

\footnotetext{
${ }^{2}$ As a result of the popularity of the 'New Public Management' philosophy (Hood, 1991; Pollitt et al., 2000) and the strong interrelation between the public and private actors in the context of public-private partnerships (cf. multi-actor governance), during the past two decades, many consultants and (consequently also) public managers have greatly favoured an order-seeking approach in Flanders.
} 
theory and practice (Healey, 1993; Forester, 1993). Followers of the complexity-acknowledging perspective argue that decisions are given form and content within a rather disorderly or chaotic process without central steering by the local government, and in which often an unplanned or accidental convergence of circumstances determines the decision-making (Cohen et al., 1972; Kingdon, 1984; Baumgartner et al., 1993; Brown et al., 1998), or whereby only very incrementally either through a learning process or not - decisions are reached (Lindblom, 1959; Wildavsky, 1969; Quinn, 1980; Mintzberg et al., 1998; Teisman, 2000).

As such, we argue that the impact of strategic plans is relative in complex decision making processes. Strategies formulated in strategic plans are, in fact, not always acted upon and even when implemented do not always achieve the intended objectives. Mintzberg et al. (1998) for example hold that strategic plans are invariably groupings of decisions that emerged in a rather incremental manner. Consequently, these management experts see strategic planning as a 'contradictio in terminis'. Planning does not lead to new strategies because in the absence of an initial strategy, there can never be a question of planning. Mintzberg et al. (1998: 76-77), however, restrict planning rather to rational-normative tools and techniques. From this perspective, plans are readily outdated since continuously new decisions are being prepared, the implementation does not go as planned, new knowledge emerges, other actors enter the field, unexpected opportunities and problems arise, etc. According to some authors, formal strategic planning is therefore often nothing more than the process of quantifying objectives as a means of control for the organisation's hierarchy (Goold \& Quinn, 1990; Mintzberg et al, 1998) or is used to reinforce the power of the central decision and the decision-maker (Teisman, 2005). They recommend other tools and techniques to deal with complex decision-making. In complex situations, organisations should aim to deal with uncertainty, ambiguity, unpredictability and 'unstable behaviour'. This requires creativity operating at the edge of chaos (Stacey, 1996; Burnes, 2005) and fits within network and process management (Klijn et al., 1997), within practices of the learning organization (Senge, 1990; Argyris, 1993; Mintzberg et al, 1998) or within 'collaborative rationality' (Innes et al., 2010). However, the perspective and analysis developed below does not aim to indicate how to manage complex decision-making processes (of UDPs), nor does it deliver direct answers to problems related to these processes. It is merely our aim to provide a contribution to a more better and more precise understanding of how and why decision making of UDPs in Flanders is complex.

In complex situations, organisations should aim to deal with uncertainty, ambiguity, unpredictability and 'unstable behaviour'. This requires creativity operating at the edge of chaos (Stacey, 1996; Burnes, 2005) and fits within network and process management (Klijn et al., 1997), within practices of the learning organization (Senge, 1990; Argyris, 1993; Mintzberg et al, 1998) or within 'collaborative rationality' (Innes et al., 2010). However, the perspective and analysis developed below does not aim to indicate how to manage complex decision-making processes (of UDPs), nor does it deliver direct answers to problems related to these processes. It is merely our aim to provide a contribution to a more better and more precise understanding of how and why decision making of UDPs in Flanders is complex.

\subsection{Inter- and intrastrategic processes}

Given these basic assumptions, our overall hypothesis is that formal strategic plans on the different levels or scales (cf. supra) have little directing power within decision-making processes, but are only one of the multiple factors directing the decision-making. We do not expect one clear decisionmaking moment ('a supreme moment'), but instead a rather intricate and intertwined series of decisions taken within an ever changing network of actors who respond, within the constraints of a bounded rationality and competing interests, to emerging exogenous factors. However, in this paper 
a distinction is made between types of UDPs. We assume that UDPs that are mainly financed and steered by private investors - although also realised in a governance setting - tend to have a less chaotic character than UDPs developed mainly by local governments and/or through intergovernmental arrangements. The logic and rationality of private investment companies tends to a more linear, causal and rational approach (cf. order-seeking perspective; Politt et al., 2000). Because they have a decisive means of power (i.c. financial resources), they often can to a large extent impose their logic onto public partners such as the city council.

If strategic plans do not constitute central features of the complex decision-making processes (i.e. around UDPs), we do need other concepts to grasp the factors that actually shape those processes. First of all, we propose to map the web of multiple strategic processes. With a strategic process we refer to a pattern in a stream of explicit and implicit strategies or decisions of an involved actor (Mintzberg et al., 1998). Every analysis of complex decision-making processes therefore requires an interstrategic approach. Such an approach does not look at one decision-making process of one involved actor at a time (nor situates it and the resulting strategic plans in causal and formal hierarchical relationship to other decision-making processes and plans), but analyses their complex, messy and non-linear intertwining. We use the concept intrastrategic processes' to refer to the streams of decisions which are in a direct or 'non-operational' way linked to the research object. As such, we obtain on the one hand a way to deal with the existing stratification typical of complex decision-making and on the other hand a vague but defensible demarcation which is necessary to position and map thoroughly the decision-making process of a UDP. Figure 1 shows schematically the inter- and intrastrategic processes of a UDP.

\section{Fig.1: Inter- and intrastrategic processes}

Simplifying, we distinguish three layers in decision-making processes. The B-lines visualizes the decision-making process of a project, namely a tangle web of strategic processes of several actors (Teisman, 2000: 945) which evolve towards a finished UDP. We call this 'interstrategic processes'. Within these processes we can find turning or bifurcation points (e.g. 'policy windows', cf. Kingdon, 1984; Baumgartner \& Jones, 1993) and/or several decisions laid down in a formal strategic document such as protocols, public-private partnerships, cooperation agreements, project master plans, etc. (cf. hexagons). So the project-oriented plans and instruments (cf. introduction) dovetail with the Blines. However, the progress of these processes are liable to (often unforeseen or emergent) exogenous factors (cf. arrows; Mintzberg et al. 1998), varying interests and power relations (Klijn, 1996; Marsh, 1998; Swyngedouw et al.; 2002; Pinson, 2009), dominant discourses (Healey, 1997), political relations, available capacities, financial possibilities, existing instruments, etc. ${ }^{3}$ The A-lines represent stable and supportive urban strategies in which the UDP is embedded. Those patterns can be implicit or explicit. In the latter case, strategic plans at the city level and spatial structural plans are pre-eminently interwoven with the A-lines. Finally, the C-lines show webs of (inter)strategic processes concerning a specific decision of an involved actor. For example, strategic processes concerning the appointment of an internal project manager by a private investment company. The arrows between $A$ and $B$ and between $B$ and $C$ make clear that processes can steer in several directions. Given the strongly interwoven nature of decision-making processes, it is - as already mentioned - often difficult to make clear demarcations, so we make the distinctions here for analytical purposes only. In reality, the A-, B- and C-lines are entangled in such ways that a figure based on a DNA string probably gives a more realistic view.

\footnotetext{
${ }^{3}$ Within the other layers we could also show bifurcation points, formal decisions and/or emergent exogenous factors.
} 


\section{Reconstructing decision-making processes}

In what follows, we assess the interstrategic approach developed in the above paragraphs to map the complex decision-making processes and the degree of steering capacity of strategic plans in three urban development projects in the Flemish city of Kortrijk (Belgium). We do so by a careful and thorough reconstruction of the decision-making processes around these three urban development processes and the role played by various strategic plans in these processes (Dahl, 1961; Huberts, 1994). We are fully aware that these reconstructions are always a (re)construction of the researcher in which the interest of the researcher, his perspective, plays a crucial role (cf. Latour, 1987). This and the fact that the researcher is not a decision maker in the governance settings of the UDPs, are the main reasons why the 'black box' of decision making cannot be opened entirely.

The selection of three different types of urban development projects within the same city allows us to test the interstrategic approach for different types of strategic processes (cf. infra) while at the same time holding the broader context reasonably constant. Given our focus on the complexity of decision-making processes, the qualitative case study approach is the most appropriate research method as it studies phenomena within their 'real-life context', thus enabling us to take full account of their complexity (Yin, 1984: 23). For our case studies we opted for several qualitative research methods and techniques (Maso et al., 1998; Miles et al., 1984). Firstly, our reconstructions of the decision-making processes are based on in-depth interviews with involved key figures. In total, we carried out 40 interviews with local and Flemish politicians, civil servants, private investors, representatives of semi-public corporations, project leaders from public agencies and academics. Some key figures have been interviewed more than once. The aim of the interviews was (amongst others) to establish how, where, when, and by whom strategic plans that are linked to the UDPs came into being and what the role of the interviewees was within the context of these processes. Secondly, our research is also based on a detailed analysis of these strategic plans and other formal or informal (policy) documents. Part 4 of this article gives an overview of this analysis. However, to identify the role of all involved strategic plans in the decision-making process (cf. part 5) we need a thorough reconstruction of this process that is mainly based on expert interviews and that duly acknowledges its complexity. This methodical triangulation method provided us with an adequate picture of the decision-making process governing these UDPs in general, and of the impact, relevance and role of strategic planning instruments in particular.

Kortrijk is a city of 74.000 inhabitants and one out of many core cities of the Flemish urban network. The city is also part of the trans-border network 'Eurometropol Lille-Courtrai-Tournai'. The three urban development projects that we analyse below are all located in downtown Kortrijk and occupy a central position in formal strategic documents of the city's administration (e.g. political agreements, strategic multi-annual plan, spatial structural plans) and/or were mentioned as being of strategic importance to the city by local politicians and city officials during the interviews. All three selected UDPs were in the process of implementation at the time of our field work (i.c. in 2007 and 2008), and are scheduled for completion in the course of the current legislature (i.c. 2007-2012). The UDPs differ in the key decision-makers involved (apart from the city council), the source of financing and other dimensions of the UDP besides the physical-spatial intervention. In particular, we studied the decision-making process of the following three UDPs:

(1) ' $\mathrm{K}$ in Kortrijk', the Foruminvest shopping complex. In the shopping area in the city centre of Kortrijk a large shopping centre with 85 shops, a designer high-rise block containing approximately 80 housing units and a large car park is to be built. The main aim is to attract missing segments and new chain stores to Kortrijk (e.g. Zara, H\&M, MediaMarkt, Hema, etc.) so that Kortrijk can again become the blossoming shopping centre it was in the 1960s, 70s and 80s. The project was 
constructed on the site that was once home a primary and secondary school. The actual works started in mid 2007. The construction time was estimated to be about 2 years. Foruminvest, a Dutch investment company, which has completed dozens of similar projects in a number of European countries, is funding and developing the entire project. This investor and the Stadsontwikkelingsbedrijf Kortrijk (SOK), an autonomous municipal company, have opted here for a public-private partnership. Foruminvest is investing EUR 160 million in its shopping centre, including a high-rise block of flats. This is at once the biggest private investment ever made in the city centre of Kortrijk. Moreover, the project is generating new initiatives such as the foundation of a Business Improvement District and a Property Fund.

(2) The Leie Improvement Project. In a nutshell this urban project involves straightening, deepening and broadening the river Leie in the centre of the city of Kortrijk to allow ships of up to 1,350 tonnes to pass. This fits in with a European decision supported by the Belgian state and incumbing on the city of Kortrijk. These works have huge urban development repercussions for the city: the demolition of 5 bridges, the construction of 7 new bridges, the laying of boulevards, parks, a skatebowl, etc. The supralocal government considered these public works more as large-scale infrastructural works dictated by technical standards. In the beginning the city did not support the works. Influenced by various actors and processes the city of Kortrijk has gradually begun - especially in the 1990s and in leaps thereafter - to see the Leie Improvement Project more as a lever for high quality urban spaces. In the end the city embraced the project with open arms to give the public areas in the city greater architectural allure and make them more attractive. Thus top architects with international reputations were attracted to design the new bridges, quays and parks. The majority of the politicians, civil servants and external parties who were interviewed in the context of our study described the Leie Improvement Project as the most radical public works in the city since many decades.

(3) Buda-island = art island. The city of Kortrijk aims to develop Buda-island, located between the arms of the Old and the New Leie, into a sort of artists' retreat. Although until now it has been difficult to overlook the health care industry's expansion on the island (e.g. rest home, service flats, crèche, etc.), an attempt is being made to use Buda-island to place the city of Kortrijk on the map in terms of culture creation and artistic development. The objectives of this island must be sought at several scales (local, regional, national and international). This is why all kinds of cultural organisations are being given infrastructure, cooperation is being stimulated between all kinds of actors through the set-up of privatised organisations, work is being done to see how specialised posttraining courses can be further developed, the workshop approach is being adopted, etc. It is essential that all this goes hand in hand with a physical-spatial element. In the spatial development project the Buda-island is incorporated in the morphological carriers of the city (i.e. river Leie and North-South ax) and much emphasis is placed on the creation of public areas and green areas.

\section{Analysis of relevant strategic plans}

We will now analyse the strategic plans possibly relevant for the decision-making process for the three selected urban projects in Kortrijk. Although supra-local strategic plans can exert a certain influence and thus intervene in the execution of similar local practices, our focus lies on the strategic instruments in use for Kortrijk ${ }^{4}$. We subdivide the complement of plans and instruments employed in the realisation of the UDPs in three scales or levels. As already mentioned (cf. part 2.2), the strategic plans at the city level and the spatial structural plans dovetail with the A-lines form figure 1 , whereas

\footnotetext{
${ }^{4}$ We can also consider certain federal and Flemish plans and initiatives as exogenous factors (cf. infra).
} 
the project-oriented instruments are situated around the B-lines. In part 5 of this article we situate these plans within the broader context of decision-making processes.

\subsection{Strategic plans at the city level}

As we shall show, none of the three UDPs sprung from discussions around the drafting of a political coalition agreement, strategic multi-annual plan or any other strategic document. The strategic decisions mentioned in these strategic documents are invariably already been decided upon for quite some time (cf. infra) and are quite widely known. These strategic documents mostly list only brief descriptions of the objectives and of the completed or planned implementation works.

With respect to (decisions regarding) the shopping complex ' $\mathrm{K}$ in Kortrijk', this is true for the political coalition agreement reached at the end of 2006, the Kortrijk strategic multi-annual plan 2007-2012, and the Kortrijk annual action plans for 2006, 2007 and 2008. It is in the annual action plan for 2005 that, for the first time, we come upon formal information about this impending urban development project, namely that negotiations are being conducted with external actors. Yet, at the start of 2004, the city of Kortrijk, the autonomous municipal corporation and the investment company Foruminvest signed a crucial agreement of intent (cf. infra). Until 2005, we do not find in neither strategic plan at the city level - nor in the economic policy plan - mention of a potential redevelopment of the shopping area, let alone about the establishment of a major shopping centre on the site.

The same applies to the Leie Improvement Project. Even in the implementation stage, the plans for this project are lagging behind the decisions. As a result - one among many others - this means that in the city's 'strategic' policy documents, such as the most recent political coalition accords, the policy letter for 2001-2006, the annual action plans for 2000 through 2008, the approach line of the administration in 2006 and the strategic multi-annual plan for 2007-2012, the Leie Improvement Project mostly occupies only a few lines or, maximum, a few paragraphs, and the reader gets just an overview of what is to happen or where the city needs to exert some pressure on the developer. Analysis of these documents further shows us that the Kortrijk City Council is not in control of the tempo of these works. For instance, this administration is each time setting out the planning for the first building phase of the Western Ring bridge in four different annual action plans $(2003,2004$, 2005 and 2006).

Likewise, the idea to turn the Buda Island into an Arts Island had in the year 2000 not yet been entertained in the political coalition agreement. The urban planner Secchi did, at the end of the 1990s, find some merit in the sanctuary character of the island, but, in the end, we cannot discover anywhere prior to 2001 anything that would resemble a kind of strategic policy and/or master plan wherein Buda Island figures as a centre for the creative industries with international appeal. What did exist at the time were plans around the expansion of the island's maintenance functions. But these were subsequently scaled back. Only during the second half of 2001, as we note in the policy letter from the City of Kortrijk for 2001-2006, do we read that the island possesses potential to become a true Arts Island in the centre of the city. In the city's annual action plans we can as of that date follow the realisations and - ever more frequently - what is being planned.

\subsection{The spatial planning tools and instruments}

It is striking that, according to most involved actors, the Kortrijk Regional Plan and the special spatial development plans have had but little impact on the form and content of the three UDPs, let alone that they put a brake on their implementation. No real problems emerged for granting the building permits. And when this could lead to problems, as was the case with the Leie Improvement Project, 
an 'open' building permit was opted for in order to leave enough scope for choice among different possibilities. In the case of the project 'K in Kortrijk', the drafting of the environmental impact report and the mobility effects report were carried out under more or less controlled conditions ${ }^{5}$.

Likewise (the discussions related to) the Flemish, provincial, and municipal spatial structural plans and the spatial implementation plans have not put their stamp on the decision-making processes for the urban projects. Only in 2006 did Kortrijk have a municipal spatial structural plan. In contrast to what is happening in some of the other Flemish central cities $^{6}$, in Kortrijk the role and impact of the municipal spatial structural plan thus remains (for the time being) non-existent in the decisionmaking processes of the urban projects that we studied. The expert interviews show that the attitude towards this new plan varies: local civil servants often hope that the municipal spatial structural plan can avoid the dominance of ad hoc solutions, while local politicians tend to experience this plan as "an artificial instrument steered by Brussels that has lost touch with the complex reality". Yet others (including both politicians and civil servants) have a resigned attitude and state that "such a plan builds on former decisions and plans, adjusts only were necessary and now and then introduces something special". Whether this plan will become a platform document for new urban projects remains very much an open question. Its steering capacity is impacted upon negatively by the lengthy drafting process, the minimal political interest in it and the relative lack of strategic choices (for a detailed explanation, see Block et al., 2008).

In concrete terms, the legally binding part of the Spatial Structural Plan Kortrijk (SSPK) ${ }^{7}$ contains a few provisions that already were applicable and/or had been decided upon elsewhere. In this regard, the SSPK mentions the following engagements of the City Council with regard to the UDP ' $\mathrm{K}$ in Kortrijk': "the directing of the project St.-Janspoort towards a multifunctional project for residential and commercial purposes", and "the drafting of a strategic retail plan designed to reinforce the range of stores within the inner city" (Leiedal, 2006). In the guiding part of the SSPK ${ }^{8}$, we find a brief description of the project, introduced by a paragraph that points out the added value and the importance of a vibrant and well-functioning shopping area in downtown Kortrijk. All of this, however, did not function as a truly directive mechanism; the discussions had already been conducted elsewhere and the broad outlines of the UDP already established much earlier. The same is true for the Leie Improvement Project and the project Buda Arts Island. For instance, the Kortrijk City Council undertakes in the said SSPK to develop Buda Island into a centre for services and the arts. In this respect, the following actions and projects are deemed to be of strategic importance: the re-establishment of the banks of the old Leie branch and the re-development of public domains. None of these actions are, however, the result of discussions conducted within the context of this spatial structural plan. For example, in the directive part of the document, it becomes evident that it pertains to choices made previously.

Also, the policy plans of the Kortrijk department 'City Development' did not provide steering guidelines for these projects. The plans submitted by the mobility civil servants were even affected to a large degree by the decision-making processes about the urban projects. In this respect, the project ' $\mathrm{K}$ in Kortrijk' caused quite a bit of confusion for the anticipated policy on the re-construction of roadways.

\footnotetext{
${ }^{5}$ For example, the investment company retained a consultant agency himself.

${ }^{6}$ In Ghent, for instance, certain urban projects are subject to choices presented in the Spatial Structural Plan.

${ }^{7}$ Legally binding for public authorities that is, not for citizens.

${ }^{8}$ This part contains goals, priorities, desired spatial structures and actions concerning spatial policy.
} 


\subsection{Project-oriented instruments}

There exists quite a lot of differences in the sort and number of formal strategic documents used in planning the progress of the UDP and/or formally establishing the cooperation among the relevant actors (e.g. cooperation agreements, pacts, protocols, implementation plans, charters, contracts, etc.). However, as to the significance of these strategic planning documents for the decision-making processes, there is no notable difference. As we show below, for each UDP that we have studied, their capacity to steer strategic processes is limited and rather than guiding these processes they group what has already been decided upon elsewhere and solely give these decisions a formal character. Even more importantly, from the interviews emerged that the actors involved do not really consider these moments of formalisation as crucial turning points in the decision-making process. Anchoring this process to these moments does not provide us with an adequate picture about its progress.

In the decision-making process for the Leie Improvement Project, new plans, protocols, pacts, and contracts were drawn up continuously. The fact alone that such actions succeeded one another at such a rapid pace already speaks volumes about their significance and about the lack of trust that reigned among the actors involved in the process. The initial plans by the Belgian administration (i.e. Administration of Waterways - AWZ), who was responsible for the management and development of the inland waterways) date back approximately 30 years. In contrast to the strategic plan of 1975, which generated relatively little animus, the 1983 strategic plan, created some opposition. Likewise the second plan (1983) was deemed to be too restrictive in scope: it took little or no account of its effects on the city's spatial and social structure. On the basis of a counter-proposal made by the city and following numerous discussions, an initial protocol between the city of Kortrijk and the federal government was drafted. Three years later, an addendum proved already necessary since important informal agreements had resulted from a new round of consultations. For a range of (primarily political) $)^{9}$ reasons, this protocol was approved only in 1992. Event then, it was not at all this new protocol that forced a break-through in the UDP, but rather the manifold informal contacts among some creative technocrats ${ }^{10}$ and a study commissioned by the inter-municipal corporation Leiedal at that time. At the closing of the eighties and start of the nineties, a number of actors polished the five implementation phases that - seen in hindsight - barely survived in the end. Their establishment happened primarily in function of the building permit and the framework building contract with building contractors. In 2001, all existing protocols were once again pushed aside and a third protocol was drawn up. This protocol, which in the end was never formally signed, primarily focused on new implementation phases (i.e. timing) and on the financing aspect ("who pays what when?"). In May 2006, when the implementation of the UDP had reached a relatively advanced stage, a pact was made with $W \& Z{ }^{11}$ wherein the city (once again) received 'binding' commitments for the further financing. In this pact, Flemish actors for the first time to a completion date for the UDP, namely 2010 , a date that, in the meantime, has been superseded and is no longer deemed feasible.

In brief, neither the various protocols, nor the planned implementation of each individual phase, nor the framework building contract, have been capable of preventing continuous alterations and changes to the project plans (e.g., bridges scheduled to be built during one phase are being constructed in another, the timing needed to be adapted at regular intervals, new ideas were added,

\footnotetext{
${ }^{9}$ In 1988-89, the Belgian Constitution was again amended to give further responsibilities to the regions and communities. Since then the Flemish region has jurisdiction over public works, housing, water policy, education, etc. in the Flanders.

${ }^{10}$ Technocrats from the city of Kortrijk, the federal administration (AWZ) and the inter-municipal corporation Leiedal searched for a solution to unblock the impasse between the city government ("no harm to the city structure") and the federal government ("the necessity of a straighter and broader river in the heart of the city").

${ }^{11}$ W\&Z is since 2004 the Flemish agency that replaced AWZ.
} 
etc.). We further note that a change in the planning also regularly led to an adaptation of some other official document (e.g. the framework building contract). Binding agreements about financing and references to the flows of funds and termination dates can barely be discovered in it. It is said that, from a legal point of view, this would in effect be impossible ${ }^{12}$. When, on the one hand, local actors keep on amending the plans and, on the other, the Flemish authorities make it known that financial promises are dependent on the Flemish budget, such kinds of documents lose a lot of their impact and credibility. Not surprising then that in the steering groups reference is seldom or ever made to these official documents. The protocols and pacts were essentially designed to formally set forth what progress had been achieved in the meantime (e.g., the determination of the construction work contours, push through the building of the Western Ring bridge, determination of the width of the Leie River, design as essential element, expanded local input, etc.).

In the 'formal' decision-making process of the project ' $\mathrm{K}$ in Kortrijk', three agreements among the actors involved are given central focus: the statement of intent of 2004, the cooperation agreement of 2005, and the (implementation) charter of 2007. This again concerns documents wherein (often accompanied by relatively slow progress) agreements are being officially consolidated. In hindsight (and up to the present day), we can state that these agreements have been satisfactorily complied with. As a marginal note, we further wish to state that some of the actors interviewed hold the view that also the 'Masterplan Spoorweglaan' formed part of the basis for the developments around the large-scale shopping centre. However, from our reconstruction of the decision-making process, this does not seem to be the case. At most, this plan has, together with other developments, prepared the way for the context to be receptive to, and prepared to follow-up on, alternative proposals by developers. And this, perhaps, primarily for the reason that the Masterplan turned out to be less than successful, judging by the results achieved ${ }^{13}$.

In the project Buda Arts Island, the first formal agreement is the formation of steering and working groups for the purpose of developing the ideas in consultation with the academic community. Programmed, legal-financial, and spatial 'concept plans' were consequently fleshed out. The proposed spatial development concept was consciously kept as an open concept seeing that the final product remains, by definition, an unknown quantity. In this respect, the concept had to be capable of integrating modified partial insights, of putting unexpected opportunities to good use, of adopting different time frames, or of grafting an added layer (e.g. an ecological one) onto the spatial platform, or of dealing with setbacks: in short, it had to be capable of handling a vision about planning that would be in harmony with complexity-acknowledging approaches. A second document that we are advancing here is the project and development plan (inclusive of a detailed cost estimate) that was drawn up in function of the Flemish subsidies for urban renewal. And finally, agreements were also made in the formation documents dealing with the autonomous municipal company Buda. This latter document is perhaps the only one more or less deserving the designation of a formal agreement that fixes the progress of the project and the relevant agreements between the actors involved in it, albeit rather at a late stage - if not 'after' - the decision-making process.

\footnotetext{
${ }^{12}$ The fact is that the minister may only on an annual basis formally approve the financial resources that have been entered into that specific investment program.

${ }^{13}$ It may well be that, in time, just the opposite will prove to be the case: the project Foruminvest can give a strong impulse to the area located around the more distant and subordinate neighbourhood 'Spoorweglaan', certainly when also the nearby and already scaffold project can realize its ambitions.
} 


\section{Conclusions and reflections}

\subsection{Strategic plans are lagging behind}

It appears from our Kortrijk cases that (formal) strategic plans on the city level and as spatial policy instruments do not lie at the basis of, and are not decisive factors in, the decision-making process of UDPs. These instruments do not form a bifurcation moment, but are merely one of the multiple factors (exerting little impact) within the tangle of inter- and intrastrategic processes that, in mutual interaction, determine the outcome. Rather, they group and describe the consequences of gradually developing strategic lines and decisions already taken previously. We note that within the contours of an urban project the drafting of a project plan, an agreement, protocol, charter or pact does not provide an incentive to, or maturation of the context for, narrowing down the moment at which crucial decisions are made. Also such project-oriented instruments consolidate concluded agreements and follow in the wake of specific defining moments or of gradually and often informally developed decisions within strategic processes rather than being a force directing decision-making processes (cf. infra). This is conform to the contention by Mintzberg et al. (1998), who see a strategic plan not only as a relative given but likewise as a 'contradictio in terminis' (cf. supra). Whether or not the plans for implementation will be executed more or less as provided for, differs from case to case.

We note from our study the absence in Kortrijk of a strong political platform for strategic planning on the city level and spatial (structural) plans. Several politicians and some officials regard strategic planning as artificial instruments that are barely in touch with the complex and unpredictable reality. Together with the complexity of decision-making processes around UDPs, and the still undeveloped or immature character of some plans ${ }^{14}$, this (also) largely explains the limited impact of these instruments, which often leads to frustration of many of the city's civil servants.

Despite the limited impact of this set of tools and instruments used in the steering of UDPs, we ought not to ignore some potential and rather indirect functions of such instruments. For instance, (strategic) plans may ensure a certain profiling and offer a holdfast for (often less involved) actors within and outside of the municipal organisational structure. We also observed that the drafting process of strategic documentation on the meso and macro levels can, ideally, generates an opportunity for all actors involved (primarily for politicians and civil servants, but this process can be further extended to include external partners) to reflect on the direction(s) where one would like to end up in the long term. The final product may be temporary and relative, yet it may well serve as a temporary ' $f i x^{\prime}$ for the organisation in question. Our analysis suggests that the added value of project-oriented instruments lies primarily in the implementation phase. An appropriate concentration and coupling of strategies, actions, and budgets can, indeed, provide for a more efficient and more effective management policy. However, in this process, one ought not to turn a blind eye to more urgent and pressing problems and opportunities, the inter-action processes within all sorts of networks and power factors that can influence the full procedural complement.

\subsection{Formal planning within complex decision-making processes}

Our inter-strategic and complexity-acknowledging approach leads us to see UDPs in Kortrijk as crossroad projects within a web of multiple strategic processes present in and beyond the city. We wish to emphasize that our three UDPS are indeed at the same time and partially cause and consequence (or lever) of implicit and explicit strategic processes. They often harmonize with one another. Every UDP is also distinguished by its own history and strongly related to a specific

\footnotetext{
${ }^{14}$ Specifically the strategic multi-annual plan and the municipal spatial structural plan (cf. supra).
} 
exogenous context. This mapped complexity could be an explanation for the specificity of the decision-making process and the limited impact of formal strategic plans.

When several strategic processes - which may, or may not, exert a strong impact on problems and opportunities that can unexpectedly and randomly emerge - can be associated with one another, when 'visionary' figures latch onto these moments, and when important actors have become convinced, chances increase that an (idea for an) urban project develops or makes a qualitative leap. Such 'inter-connectivity' that lies at the basis of our three cases did not appear to be linked to the drafting of a (formal) strategic plan. In the urban project ' $\mathrm{K}$ in Kortrijk' obvious use is being made of a 'policy window' (Kingdon, 1984). In a nutshell: Kortrijk lived for far too long on former success stories and did not sufficiently invest in its shopping area, while nearby cities increasingly entered into competition to attract shoppers, several shopping centra were built on the outskirts of the town, chain stores left the city centre (problems), an autonomous municipal company was established by means of Flemish initiatives, small interventions in the commercial area were not successful (failure of alternate policy), a secondary and high school closed down in the shopping area (catalyst), the investment company Foruminvest suggested a drastic intervention and change of course (solution), etc. In both of the other cases it is the creativity of certain stakeholders that plays a role in the search for solutions and the development of opportunities. Some technocrats overcame the impasse of the Leie Improvement Project (cf. supra, 4.3) and in the Buda-island project processes and opportunities were picked up, bundled and stimulated by mayor De Clerck (politics and entrepreneurialism).

These facts do not, however, signify that it is a simple matter to determine when precisely an idea for an urban project originates. Multiple moments are determining this process and actors involved often perceive the process in a different light. With reference to the outcome of our cases, the reification of an idea appears likewise to correspond to a 'point of no return'. This is not, by definition, the case. Not only do proposals for new urban projects often remain mired within an embryonic stage, and this for a number of reasons ${ }^{15}$, we also note that actors involved most often situate the actual turning point for an urban project at different moments in time. It makes little sense to focus on one single turning point, or a bifurcation point, in the progress of an urban project, even when it is separated from a formal plan. Whereas in the decision-making process around the shopping complex ' $\mathrm{K}$ in Kortrijk' we can identify a succession of a limited number of crucial decisions, we note with the two other cases even a whole series of strategic processes and turning points. Here too, such moments appear to sometimes differ in their perception. As such, it is not the case that, in the first place, all alternative solutions to a problem and their anticipated effects are listed, followed by choosing the solution that scores the best on the basis of a cost-benefit analysis ('the supreme moment'), then to cast everything into a formal implementation plan and, subsequently, to execute this plan under control. That kind of linear progression is, however, an ideal-typical description that can primarily be found in prescriptive frameworks and hardly ever in descriptive approaches. We do, nonetheless, see their appearance in a less pure form, namely in the case involving the shopping complex ' $\mathrm{K}$ in Kortrijk'. As stated supra, this project finds its origin at a time when various streams (i.c. problems, alternatives, happenings, and political developments) are all converging rather unexpectedly and the strategy of Foruminvest, as it were, absorbs and changes the other strategies. Afterwards, this translates into a fairly phased and causal decision-making process around a relatively easy to mark out infrastructural project. The bundled decisions and project plans are, in effect, executed relatively unchanged, both concerning their content and timing. The cases of Buda Arts Island and the Leie Improvement Project have a more chaotic (i.e. non-linear) character and, hence, demonstrate rather the characteristics that we find also in complexity-acknowledging theories. The

\footnotetext{
${ }^{15}$ This is a large 'black box' that is seldom or never of any consequence within the decision-making research.
} 
progress of the decision-making process can, indeed, run very gradually, sometimes by leaps and bounds, then again, in a zigzag line. We observe on different levels chains of explicit and implicit decisions by several actors that are interwoven rather capriciously (i.e. anticipate or build further on each other), we are confronted with emerging exogenous factors that are interpreted and framed variously by the actors involved, and the present power configurations within the urban governance networks can to a large extent be typified as a political arena wherein numerous informal channels are at play.

Our research in the city of Kortrijk hints that actors involved in UDPs should keep in mind the perhaps intrinsic unpredictability and should try to anticipate in a creative way (instead of holding to a linear and causal management approach). Further research, however, must show to what extent our conclusions concerning the impact of formal plans are transferable to other types of cities, urban projects and complex decision-making processes.

\section{Acknowledgements}

This article is based on broader Ph.D. research of Thomas Block on decision-making processes and power configuration in UDPs. This research was conducted within the Centre for Local Politics (Ghent University) and supported by the Research Foundation Flanders (FWO). An earlier version of this article was presented at the international EURA/UAA-Conference 'City Futures in a Globalising World' (Madrid, 4-6 June 2009).

\section{Bibliography}

ALLISON, G. (1971) Essence of Decision. Explaining the Cuba missile crisis. Boston: Little Brown.

ARGYRIS, C. (1993) On Organizational Learning. Cambridge, MA: Blackwell.

BAUMGARTNER, F.R. and JONES, B.D. (1993) Agendas and Instability in American Politics. Chicago: University of Chicago Press.

BLOCK, T., DE RYNCK, F., REYNAERT, H. and STEYVERS, K. (2008), De ondraaglijke lichtheid van papier. Resultaten van een kwalitatief onderzoek naar strategische meerjarenplanning in de stad Kortrijk, in REYNAERT, H., BLOCK, T. and STEYVERS, K. (Ed) Stratego of stijloefening? Strategische meerjarenplanning in lokale en provinciale besturen. Brugge: Vanden Broele, pp. 15-50.

BOUDRY, L., LOECKX, A., VAN DEN BROECK, J., COPPENS, T., PATTEEUW, V. and SCHREURS, J. (2006) Inzet / Opzet / Voorzet. Stadsprojecten in Vlaanderen. Antwerpen: Garant.

BOWMAN, E. (1995) Strategic History: Through Different Mirrors. Advances in Strategic Management, 11, A, pp. 25-45.

BROWN, S. and EISENHARDT, K. (1998) Competing on the Edge. Strategy as Structured Chaos. Boston: Harvard Business Press.

BURNES, B. (2005) Complexity theories and organizational change. International Journal of Management Reviews, 7, 2, pp.73-90.

CHAFFEE, E. (1985) Three models of strategy. Academy of Management Review, 10, pp. 89-98.

COHEN, M.D., MARCH, J.G. and OLSEN, J.P. (1972) A garbage can model of organizational choice. Administrative Science Quarterly, 17, pp. 1-25. 
DAHL, R. (1961) Who Governs? Democracy and power in an American city. New Haven: Yale University Press.

DE SOLA MORALES, M. (1989) Another Modern Tradition. From the Beak of 1930 to the Modern Urban Project. Lotus, 62, pp.6-32.

FALUDI, A. (2000) The performance of spatial planning. Planning, Practice \& Research, 15, 4, pp. $299-318$.

FLYVBJERG, B. (1998) Rationality and Power. Democracy in Practice. Chicago and London: University of Chicago Press.

FORESTER, J. (1993) Learning from practice stories: the priority of practical judgement, in FISHER, F. and FORESTER, J. (Eds) The Argumentative Turn in Policy Analysis and Planning. Durham: Duke University Press, pp. 186-209.

GOOLD, M. and QUINN, J.J. (1990) The paradox of Strategic Controls. Strategic Management Journal, 11, pp. 43-57.

HEALEY, P. (1993) Planning through debate: the communicative turn in planning theory, in FISHER, F. and FORESTER, J. (Eds) The Argumentative Turn in Policy Analysis and Planning. Durham: Duke University Press, pp. 233-253.

HEALEY, P. (1997) Collaborative planning. London: Macmillan Press.

HOOD, C. (1991), A public management for all reasons? Public Administration, 69, 1, pp.3-19.

HUBERTS, L.W.J.S (1994) Intensieve procesanalyse, in HUBERTS, L.W.J.S, KLEINNIJENHUIS, J. and BOS, J.M. (Eds) Methoden van invloedsanalyse. Amsterdam: Boom, pp. 38-60

INNES, J. and BOOHER, D. (2010) Planning with complexity: An introduction to collaborative rationality for public policy. New York: Routledge.

JOHNSON, G. and SCHOLES, K. (2002) Exploring public sector strategy. Essex: Pearson Education Ltd.

KINGDON, J.W. (1984) Agendas, alternatives and public policies. Boston: Little, Brown and Company.

KLIJN, E.H. (1996) Analyzing and managing policy processes in complex networks: A theoretical examination of the concept Policy Network and its problems. Administration \& Society, 28, 1, pp.90-119.

KLIJN, E.H. and TEISMAN, G.R. (1997) Strategies for network management, in KICKERT, W.J.M., KLIJN, E.H. and KOPPENJAN, J.F.M. (eds.) Managing Complex Networks. London: Sage.

LATOUR, B. (1987). Science in Action: How to Follow Scientists and Engineers through Society. Cambridge, MA: Harvard University Press.

LEIEDAL (2006) Gemeentelijk Ruimtelijk Structuurplan Kortrijk. Kortrijk: Intercommunale Leiedal i.s.m. de Stad Kortrijk.

LINDBLOM, C. (1959) The Science of Muddling Through. Public Administration Review, 19, 2, pp. 79-88.

MACLEOD, G. and GOODWIN, M. (1999) Space, scale and state strategy: rethinking urban and regional governance. Progress in Human Geography, 23, 4, pp. 503-527.

MARSH, D. (ed.)(1998) Comparing Policy Networks. Buckingham: Open University Press.

MASO, I. and SMALING, A. (1998) Kwalitatief onderzoek: praktijk en theorie. Amsterdam: Boom. 
MILES M.B. and HUBERMAN A.M. (1984) Qualitative Data Analysis: A Sourcebook of New Methods. Newbury Park, CA: Sage.

MINTZBERG, H. (1994) The Rise and Fall of Strategic Planning. Hemel Hempstead: Prentice Hall.

MINTZBERG, H., AHLSTRAND, B. and LAMPEL, J. (1998) Strategy Safari. A Guided Tour Through the Wilds of STRATEGIC MANAGEMENT. NEW YORK: FREE PRESS.

MOLOTCH, H. (1976) The city as growth machine. American Journal of Sociology, 85, 2, pp.309-355.

MOULAERT, F. (2002) GLOBALIZATION AND INTEGRATED AREA DEVELOPMENT IN EUROPEAN CITIES. OXFORD: OXFORD University Press.

PINSON, G. (2006) Projets de ville et gouvernance urbaine. Revue Française de Science Politique, 56, 4, pp.619651.

PINSON, G. (2009) Gouverner la ville par projet. Urbanisme et gouvernance des villes européennes. Paris : Presse de Science Po.

POLLITT, C. and BOUCKAERT, G. (2000) Public Management Reform. Oxford: Oxford University Press.

QUINN, J.B. (1980) Strategies for Change: Logical Incrementalism. Homewood: Irwin.

REYNAERT, H., BLOCK, T. and STEYVERS, K. (2008) Stratego of stijloefening? Strategische meerjarenplanning in lokale en provinciale besturen. Brugge: Vanden Broele.

SALET, W. and GUALINI, E. (eds.) (2006) Framing strategic urban projects. Learning from current experiences in European Urban Regions. London: Routledge.

SENGE, P.M. (1990) The Fifth Discipline. London: Century Business.

SIMON, H.A. (1947) Administrative Behaviour. A study of decision-making processes in administrative organisation. New York: Free Press.

SMITH, G. and MAY, D. (1980) The artificial debate between rationalist and incrementalist models of decisionmaking. Policy and Politics, 8, pp.147-161.

STACEY, R.D. (1996) Complexity and Creativity in Organizations. San Francisco: Berrett-Koehler.

SWYNGEDOUW, E., MOULAERT, F. and RODRIGUEZ, A. (2002) Neoliberal Urbanization in Europe: Large-Scale Urban Development Projects and the New Urban Policy. Antipode, 34, 3, pp. 542-577.

TEISMAN, G. (2000) Models for Research into Decision-Making Processes: On Phases, Streams and DecisionMaking Rounds. Public Administration, 78, 4, pp. 937-956.

TEISMAN, G. (2005) Publiek Management op de grens van chaos en orde. Over leidinggeven en organiseren in complexiteit. Den Haag: Sdu Uitgevers.

VAN HELDEN G.J. AND JANSEN, E.P. (2003), New Public Management in Dutch Local Government. Local Government Studies, 29, 2, pp. 68-88.

WILDAVSKY, A. (1969) Rescuing policy analysis from PPBS. Public Administration Review, 29, 2, pp. $189-202$.

YIN, R.K. (1984) Case study research. Design and methods. London: Sage. 